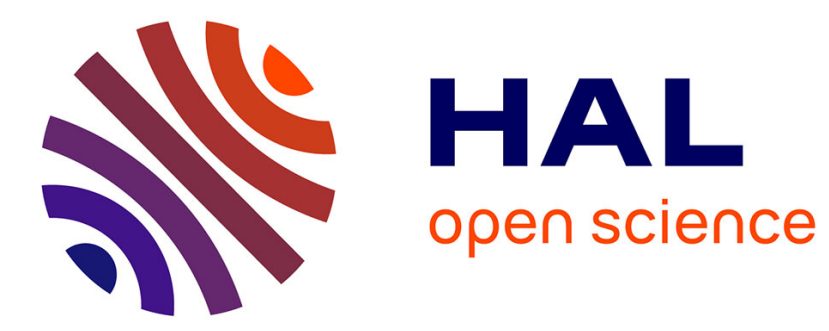

\title{
Teachers' instrumental geneses when integrating spreadsheet software
}

\author{
Mariam Haspekian
}

\section{To cite this version:}

Mariam Haspekian. Teachers' instrumental geneses when integrating spreadsheet software. ClarkWilson, Alison, Robutti, Ornella, Sinclair, Nathalie The Mathematics Teacher in the Digital Era, 2, SPRINGER, pp.241-275, 2014, 978-94-007-4637-4. 10.1007/978-94-007-4638-1_11 . hal-01002961

\section{HAL Id: hal-01002961 https://hal.science/hal-01002961}

Submitted on 1 Feb 2016

HAL is a multi-disciplinary open access archive for the deposit and dissemination of scientific research documents, whether they are published or not. The documents may come from teaching and research institutions in France or abroad, or from public or private research centers.
L'archive ouverte pluridisciplinaire HAL, est destinée au dépôt et à la diffusion de documents scientifiques de niveau recherche, publiés ou non, émanant des établissements d'enseignement et de recherche français ou étrangers, des laboratoires publics ou privés. 


\title{
Teachers' instrumental geneses when integrating spr eadsheet software
}

http://www.springer.com/fr/book/9789400746374

\section{Mariam Haspekian}

EDA, University Paris Descartes

mariam.haspekian@parisdescartes.fr

\begin{abstract}
The spreadsheet is not a priori a didactical tool for mathematics education. It may progressively become such an instrument through the process of professional geneses on the part of teachers. This chapter describes the beginning of such a genesis, and presents some results concerning teachers' professional development with spreadsheets by examining the outcomes of two different sets of data. Theoretical notions, such as instrumental distance and double instrumental genesis supported the analysis of data leading to a comparison of a teacher who is integrating spreadsheets for the first time in her practices with the practices of teachers who are more expert with spreadsheets. The similarities found in the ways they use the tool leads to some hypotheses on the importance of these common elements as key issues in teachers' ICT practices.
\end{abstract}

Keywords: mathematics teaching and learning, teaching practices, ICT integration, professional learning of mathematics teachers, technology-mediated classroom practices, spreadsheet, professional/ personal instrument, double instrumental geneses (professional/ personnal), instrumental distance, novice/ expert teacher

\section{Introduction}

Around the 1980s, the idea that ICT could serve school learning, in particular mathematical learning began to develop. The current picture is that the use of ICT in classrooms is prescribed in the curricula of many countries, which can include detailed recommendations for teachers (Eurydice, 2004, p.24). However, many reports comment upon the poor integration of ICT in mathematics teaching. Today, after an enthusiastic period claiming ICT benefits for learning mathematics, researchers describe a phenomenon of disappointment. It is a fact that ICT potentialities are rather poorly exploited and that ultimately, technology integration is very limited. For example, using data from PISA 2003, Eurydice (2005) reported that less than half of students are familiar with activities such as using a spreadsheet to plot a graph. One of the reasons for this, which has been put forward by many studies, is the "teacher barrier" (see for instance Ruthven, 2007 or Balanskat, Blamire \& Kefala, 2006). This is why it seems crucial to advance our knowledge of teachers' 'usual practices' alongside their technologymediated ones and pose questions such as: How do ICT practices develop and evolve in time? What do we know about the instrumental geneses with ICT and about teachers' resistances? My own doctoral research (Haspekian 2005a) led me to look for reasons beyond those that are often cited: lack of time; lack of training; 
lack of material; conservatism etc. Without denying these factors, my research claimed that there are deeper reasons for teachers' resistance, related to the impact that technology has on the mathematics to be taught, and the difficulty, for teachers in managing this impact. Therefore, it remains important to advance our understanding of this impact and the ways that teachers account for it.

With this purpose in mind, this chapter aims to provide an insight into teachers' practices with technology by comparing the results of different studies concerning the same technology, the spreadsheet (Haspekian 2005a, 2011). The first two studies formed different parts of my doctoral study. These were an observation of a teacher, called $\mathrm{Ann}^{1}$, who was integrating spreadsheet for the first time in her practices and an inquiry interviewing and comparing pre-service teachers with teachers who were "experts" with spreadsheets ${ }^{2}$. The third study resulted from another research proect, which observed ICT sessions in ordinary classrooms, during which I happened to return to Ann's classroom. Thus, I had the opportunity to observe her practice a year later. Hence these studies provide an opportunity to make an interesting comparison concerning teachers' practices with spreadsheets at different stages of integration:

- pre-service teachers;

- teachers who are expert with spreadsheets;

- a teacher who is neither a novice, nor an expert with ICT.

This comparison involved two theoretical frameworks. The instrumental approach (Artigue 2002, $\square$ uin, Ruthven \& Trouche 2004), which was developed around the concept of instrumental genesis, supported an analysis of the impact of the spreadsheet on mathematics. This led me to determine both the didactical potential of spreadsheets and the difficulties that might occur as the spreadsheet introduced new elements and changes to the mathematics that was to be taught. The second framework was the didactic and ergonomic aproach (Robert \& Rogalski, 2002), which helped to describe teachers' activity. In the secnd section of this chapter, this was used alongside the instrumental approach to help me to understand Ann's evolution over two years. The third section probes Ann's practices more deeply by comparing her evolution with the practices of the "expert" teachers. This will highlight some results about the development of ICT use in teachers' practices concerning the way that their practices evolve and the difficulties they encounter when integrating spreadsheet technology.

\section{ICT and mathematics education: the case of the spreadsheet}

An increasing number of technologies can be found in todayôs mathematical school landscape, from pocket calculators adapted for the elementary school through to universitiesôvirtual learning environments that include interactive exercises and complete courses for various domains of mathematics. Among these tools, in France the spreadsheet is officially prescribed for use in junior high and high schools, especially for the teaching and learning of algebra. However, this tool was neither created for, nor has it been adapted to, mathematics learning. The origins of the spreadsheet are quite remote from the educational world in accountancy (see Bruillard and Blondel 2007 for a historical and economical approach of the creation of the spreadsheet). Yet, to know how to calculate with a spreadsheet, in particular by using a formula, is a competency required in the curricula of an increasing number of countries across the world (Pelgrum \& Anderson 2001). Prior to the existence of spreadsheets the use of computer tools required competencies in programming and thus, the learning of a programming language. The spreadsheet provided, for the first time, a way to avoid the need to program, leading Baker and 
Sugden (2003, p.18) to say, ñNowhere is its application becoming more marked than in the field of educationò. However, in spite of some isolated experiments to adapt them for education, the spreadsheets remains a tool for the business world, with an increasingly sophisticated set of functionalities that have been designed in response to business rather than educational demands.

The poor integration of spreadsheets within mathematics teaching contrasts with other educational software such as dynamic geometry software ${ }^{3}$. This seems to offer a contradiction in that, even if some researchers question the relevance of spreadsheet in mathematics education, the ma ority of the research highlights spreadsheets' potential benefits for students. A brief synthesis on this theme turns the attention to the teaching and learning of algebra as I examine these tendencies in the light of the instrumental approach in order to analyse further the characteristics and complex relations of the spreadsheet with mathematics.

\section{Potential uses of the spreadsheet for mathematicslearning: an overview of research literature}

I begin by asking "What mathematical topics can be engaged through the use of spreadsheets at school?" The field that comes to mind most naturally is that of statistics. However, a closer examination of the operations of the spreadsheet reveals the algebraic nature of such activity. Without going into technical details ${ }^{4}$, one can note that from a historical point of view, the relation with algebraic concepts had been long identified.

le premier tableur connu serait le áalcolatore tabulare meccanico automaticoô ou calculateur tabulaire mécanique automatique de Giovanni Rossi (1870), qui a permis une avancée décisive dans la relation entre lôlgèbre matricielle et les matrices comptables. (Cilloni \& Marinoni 2006, Cilloni 2007). (in Bruillard, Blondel \& Tort 2007)

The first known spreadsheet would be the 'calcolatore tabulare meccanico automatico' or automatic mechanical tabular calculator from Giovanni Rossi (1870), who permitted a key advance in the relationship between matrix algebra and financial matrices. (Cilloni \& Marinoni 2006, Cilloni 2007). (in Bruillard, Blondel \& Tort 2007)

The ability to link cells by formulas is the source of the spreadsheets' effectiveness. Many research studies affirm then the potentialities for the learning of algebra (algebraic ob ects, modes of treatment, problem solving) by analysing the new opportunities that spreadsheets offer alongside the operational constraints of their use. The new possibilities concern:

- the interactivity, allowing feedback richer than paper and pencil (for example, the numeric feedback of a formula helps students to con ecture or detect errors);

- the capacity for calculation (automatic recopying of formulas, and instantaneous reactualisation of the results);

- the articulation of multiple registers of representation (natural language, formulas, numbers and graphics).

The benefits of spreadsheets, which can derive from the constraints of use, relate to both the symbolic language and the methods for solving mathematical problems with them. The symbolic requirement is due to the tool it- 
self as opposed to didactic contract that is usually entered into when students begin to encounter algebra involving the unmotivated use of letters that competes with non-algebraic strategies ${ }^{5}$. Spreadsheets also compel students to plan their work, organise their worksheet and, in doing so, anticipate the possible feedback from the technology.

For most researchers (Ainley, Bills \& Wilson 2003, Ar arello Ba $\square$ ini \& Chiappini 2001, Capponi 1999, Dettori, $\square$ arutti \& $\square$ emut 2001, Ro ano \& Sutherland 1997), these potential benefits place the spreadsheet between arithmetic and algebra. This intermediate position is seen to be ideal for the learning of algebra. For instance, Ro ano and Sutherland (1997) conclude that the spreadsheet supports a smooth transition for pupils' initial numeric methods towards algebraic ones. In a previous study I showed that by comparing arithmetic, algebraic and spreadsheet soltution methods for the same problem ${ }^{6}$, the spreadsheet adds some algebraic characteristics to an arithmetic procedure (Haspekian, 2005b). For others, spreadsheets could help to overcome the semantic/syntactic difficulties of algebra. In Ar arello and al. (2001), the complexity of algebra is interpreted as a difficulty for pupils to enter the "game of interpretation" between the algorithmic and symbolic functions of algebra. The various registers of representation of the spreadsheet are then seen as a tool helping the pupils to enter this "game" through the construction and interpretation of formulae.

These potential benefits of spreadsheets contrast with the previous discussion of their weak integration. In the reality of the classroom, after having been introduced to them within the study of algebra, students use them rarely during their time at secondary school. The results of the DidaTab pro ect (Bruillard and al., 2008) showed that the high school students from regions where the spreadsheet is most used do not have higher competences than average, except for the competencies of selectinf and formatting cells. More generally, the research concludes that all of the 288 students involved in the study:

seem to manage the óurfaceôcomponents, such as formatting the cells and the tables, but the mastery of the essential functioning of the spreadsheet, the writing of formulas, and the knowledge of its constituant elements (operators, operands, references, functions...) is not demonstrated by the large majority of students.

Capponi (1999) adopts a more moderate position about the potentiality for spreadsheets. His view is that the intermediate position of the spreadsheet between arithmetic and algebra may allow the pupil remain entirely on the arithmetic side without ever noticing the algebraic aspects ${ }^{7}$. Capponi quotes, for example, the display or editing of a formula which centers the user on the numeric aspects (computation results, designation of numbers) to the detriment of the underlying algebraic aspects (formulas, and cell references that play the role of variables).

So the question becomes, how can we support pupils to build algebraic knowledge with this tool? All of the above-mentioned researchers underline the importance of the didactical design of the situations but say little about these situations, such as how to create them, and on which variables to focus the teaching. In many spreadsheet resources that have been published on professional websites one can identify the mathematical variables used, while the "instrumental" variables (the tool features) remain mostly implicit. $\square$ et, if these elements are not examined, they may generate misunderstandings, resulting in the pupils using spreadsheets in ways "other" than what expected. The organisation of the teaching (didactical and mathematical), the way the tool is introduced, its links to mathematics, the techniques taught, their links with the mathematical techniques already learned (or to be learned) in paper and pencil environment, the role of the teacher and her didactic managements are all elements that must be created by the teacher. For instance, how and when does the teacher introduce into the lesson the important technical specificities of spreadsheets, such as the functionality of dragging? How does 
the teacher structure the teaching so that the ideal didactic potentialities of the spreadsheet become actual? Again, the question of linking the tool features with mathematical concepts arises, revealing that the work will be different from work in the paper and pencil environment. What exactly are these differences and what impact could they have? These questions echo those that were central to research leading to the instrumental approach (Artigue 2002, $\square$ agrange 1999, Dri vers 2000, $\square$ uin and Trouche 2003). This particular theory showed the importance of instrumentation and its relation to conceptualisation within CAS environments, another type of tool, like spreadsheets, that was not initially created for teaching. These issues lead directly to the theoretical con struct that is instrumentation, which allows us to understand more clearly and resolve the problems of technological integration, by showing the need to take account of the process of instrumental geneses.

\section{The instrumental approach: Some theor etical elements}

ICT use in mathematics education is a domain within the more general area of technology use in human activity, which has been studied within the field of cognitive ergonomics. A psychological and socio-cultural theory of instrumentation, developed in this field provides a frame for tackling the issue of learning in complex technological environments ( $\square$ rillon and Rabardel, 1995; Rabardel, 1993, 1999). The instrumental approach in didactics took some elements of this frame, including two of its key ideas: the artefact/instrument distinction, and the fact that using a tool is not a one-way process; rather, there is dialectic between the sub ect acting on his/her personal instrument and the instrument acting on the sub ect's thinking ${ }^{8}$. Within the activity of a sub ect, an artefact ${ }^{9}$ becomes an instrument through a long individual process of instrumental genesis, which combines two interrelated processes: "intrumentalisation" (the various functionalities of the artefact are progressively discovered, and may be transformed in personal ways) and "instrumentation" (the progressive costruction of cognitive schemes of instrumented actions).

The two processes also indicate that the instrumental geneses are not neutral for the sub ect: instruments have impact on conceptualisation. For example, using a graphic calculator to represent a function may play on pupils' conceptualisations of the notion of limit. This idea of non-neutral "mediation" provides a way to report on the strong overlaps that exist, and have always existed, between mathematics and the instruments of the mathematical work. It has been used in several research studies on symbolic calculators in mathematics education (Artigue 2001, ־agrange 1999, Dri vers 2000, $\square$ uin, Ruthven \& Trouche 2005).

In what follows I articulate in more detail the two notions that were used

- instrumental distance (Haspekian 2005b), which will be used to analyse relations between spreadsheet and mathematics;

- instrumental genesis which will give more precisely a phenomenon of double instrumental genesis within the context of analysing teaching practices. Indeed, for students, the spreadsheet may become a mathematical instrument through an instrumental genesis. But as a spreadsheet is not given as a didactical tool to serve mathematics education, it also has to progressively become such an instrument during a professional genesis on the part of teachers. These are two different instruments, which both existing for the teacher. 


\section{Instrumental Distance}

In French curricula, dynamic geometry software is prescribed with as much emphasisi as spreadsheets. However, the former find a better integration in mathematics classrooms than the second does. The notion of distance to the referential environment seems to play an important role in the explanation of this phenomenon (Haspekian 2005a). It intends to take into account, beyond the "computer transposition" (Balacheff, 1994), the set of changes (cultural, epistemological or institutional) introduced by the use of a specific tool in mathematics "praxis". For a given tool, if the distance to the "current school habits" is too great, this acts as a constraint on its integration (Haspekian, 2005b). On the other hand, the didactical potential of technology relies on the distance it introduces regards to paper-pencil mathematics as, for instance, by providing new representations, new problems, increasing calculation possibilities, etc. This is the case for the dynamic figures in geometry softwares, with respect to the static figures in paper-pencil geometry. The didactic potentialities of these dynamic ob ects and their benefits for students' learning have been evidenced by many research studies, (see for example $\square$ aborde 2001). For the concept of "figure", a central ob匹et on geometry, the dynamic geometry does not only broaden the conception of such obects but it offers a representation that corresponds more closely to the abstract concept of "figure" than its paper-pencil equivalent. The dynamic dimension helps to realise the famous distinction of spacial drawing/geometrical figure ( $\square$ aborde 2001, Par $\square$ ys $\square$ 1988, $\square$ aborde et Capponi, 1994). One can also consider the interesting possibility of creating new types of geometrical problems for students by varying the different tools available in the toolbars of this software. $\square$ eometric construction problems can be completely different as a result of the suppression of traditional geometric tools or through the addition of new tools by the creation of macro-constructions.

Four types of elements have been brought out that can generate such instrumental distance (Haspekian 2005a). Some of these elements relate directly to the computer transposition, such as the representations and the associated symbolism. Some others are of different nature: institutional, or didactical (vocabulary, field of problems whose solution they allow, etc.), and epistemological (i.e. what gives a tool an epistemological legitimacy). For example, the vocabulary in spreadsheets is far from the mathematical one, teachers must even create it by themselves ${ }^{10}$. There is no official reference to help the mathematics teacher to relate this vocabulary (and the obects within spreadsheets) to their mathematical equivalents. Many questions arise for teachers, such as:

- What is a cell?

- Is it a variable?

- What is a column (or a row)?

- Is it a set of several variables, or another representation of a unique variable?

- What is a relative address? Is there an algebraic equivalent?

- What is 'filling/dragging down' (a gesture embodying the concept of "formula"?)

- Is the numeric feedback: a number? a result of a formula? the permanent appearance of the cell containing a formula whereas the formula itself would be its temporary appearance? etc.

In fact, beyond the computer transposition that modifies the mathematical ob ects, the modification, from an institutional point of view, actually concerns the whole ecology of these ob ects as the tasks, techniques, and theories can all be modified. The idea of "distance" reflects this gap between the praxeologies" associated to two different environments (considering paper-pencil as a peculiar environment of mathematical work). As for the epistemological aspect, distance relates to the teachers' personal component (their representations of mathemat- 
ics, of teaching, of the role this tool plays in the development of mathematics etc.). This idea is developed later in the chapter.

In what follows, I apply this instrumental approach to the spreadsheet for the teaching and learning of algebra in order to study the impact of the spreadsheet on algebra (the ob ects, techniques and symbolisations) through the notion of distance between paper-pencil algebra and algebra with spreadsheets. The relationship between spreadsheets and mathematics is not simple as mathematical knowledge is needed to achieve spreadsheet mastery.

\section{Mathematics within spreadsheet objects}

Some computer characteristics within spreadsheets do not strictly correspond to mathematical knowledge transposed to a computer environment, or even to a computer transposition of school knowledge, however they are linked with mathematics. The basic principle of the spreadsheet, which consists of connecting cells by formulas, gives an example of these ob ects, linking spreadsheets to the domain of algebra. Such a particular relation with mathematics is precisely the reason why many studies in didactics from different countries give spreadsheets a positive role in the learning of elementary algebra, identifying them as tools of an arithmeticalgebraic nature (Ainley (1999); Ar־arello et al. (2001); Capponi (2000); Dettori et al. (1995) or Ro ano and Sutherland (1997)). But, in spite of the apparent simplicity of use of speadsheets, it is not so evident for teachers to take advantage of their characteristics. In (Haspekian, 2005a) I showed that the tool generates some complexity as it transforms the ob ects of learning and the solution strategies by creating new modalities of actions, new ob ects, and by modifying the usual ob ects, such as: variable, unknown, formula; and equation.

For example, in the paper and pencil environment, variables in formulae are written by means of symbols (generally a letter for the school levels concerned here). This 'letter variable' relates to a set of possible values (here numerical) and it exists in reference to this set. In a spreadsheet, let us take for example the formula for square numbers. Fig. 1 shows a cell argument A2 and a cell B2 where the formula was edited, referring to this cell argument.

\begin{tabular}{|c|c|c|}
\hline & $\mathrm{A}$ & $\mathrm{B}$ \\
\hline 1 & & \\
\hline 2 & 5 & $=\mathrm{A} 2^{\wedge} 2$ \\
\hline
\end{tabular}

Figure $1 \mathrm{~A} 2$ is the cell argument, B2 calculates the square of the value in A2.

Here again the variable is written with symbols (those of the spreadsheet language) and exists, as with the paper and pencil environment, in reference to a set of possible values. But this referent set (abstract or materialised by a particular value, e.g. 5 in Fig. 1) appears here through an intermediary, the cell argument A2, which is simultaneously: 
- an abstract, general reference: it represents the variable (indeed, the formula does refer to it, making it play the role of variable);

- a particular concrete reference: here, it is a number (in case nothing is edited, some spreadsheets attribute the value 0 );

- a geographic reference (it is a spatial address on the sheet);

- a material reference (as a compartment of the grid, it can be seen as a box).

So, whereas in a paper and pencil environment, we would place a set of values, here we have an overlapping cell argument, bringing with it, besides the abstract/general representation, three other representations that do not have an equivalent represention in paper and pencil (Fig.2). Other examples of spreadsheets' impact on algebra are given in Haspekian 2005a.

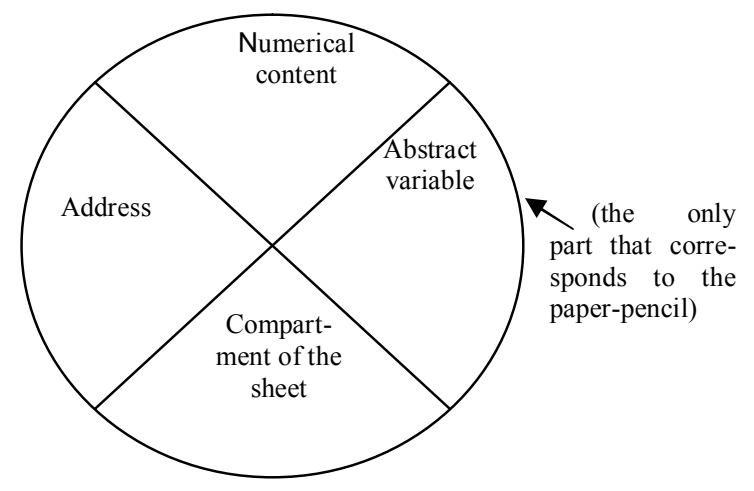

Fig. 2: The "cell variable"

From an institutional point of view, these changes have different impacts depending on the range of ways that algebra is introduced. As one of the previous ICMI studies has showed (Stacey et al., 2004), different aspects of algebra can be focused on: a tool of generalisation; a tool of modellin; or a tool to solve arithmetical, geometrical or everyday life problems through the, so called, Cartesian analytical method. Depending on the focus, different mathematics are brought to the fore, variables, formulae and functions on one hand, unknowns, equations and inequalities on the other hand. The traditional French school culture adopts the analytic approach. The resolution of various problems through the solving of equations is emblematic of pupils' introduction to algebra. Table 1 provides a brief insight into the distance between the algebraic culture in the French secondary education and the algebraic world that is characteristic of spreadsheets.

\begin{tabular}{|l|l|l|}
\hline "Values" of algebra & In paper-pencil envir onment & In the spr eadsheet envir onment \\
\hline Ob $\_$ects & unknowns, equations & variables, formulae \\
\hline Pragmatic potential & $\begin{array}{l}\text { tool for resolution of problems } \\
\text { (sometimes involving proof })\end{array}$ & tool of generalisation \\
\hline Process of resolution & $\begin{array}{l}\text { algorithmic process, application of } \\
\text { algebraic rules }\end{array}$ & $\begin{array}{l}\text { arithmetical process of trial and } \\
\text { improvement }\end{array}$ \\
\hline$\square$ ature of solutions & exact solutions & exact or approximate solutions \\
\hline
\end{tabular}


Table 1: The distance between different "algebraic worlds"

Beyond the vocabulary, it is the whole set of the 'valued algebraic' ob ects that is modified in the spreadsheet environment. Within the paper and pencil algebra of unior high schools in France, the move is from algebra as a tool of resolution where equations and unknowns are valorised, towards the algebra of variables and formulae in their functional aspect, where algebra is more seen as tool of generalisation.

Overall, the mathematical culture sustained by spreadsheets is an "experimental" one of approximations, conectures, graphical and numerical resolutions, implementing everyday life/concrete problems, statistics, etc. Thus, this vision does not fit with the one usually attached to traditional mathematics in the secondary school of the French education system.

\section{What are the consequences of such changes for the teaching?}

The idea of distance allows one of the conditions of viability of an instrument in teaching to be translated by considering the whole set of modifications that it introduces, not only at the level of computer transposition, but also through the cultural, epistemological and institutional aspects (Haspekian 2005b).

In the case of the spreadsheet for algebra, this distance seems to play a role in the teachers' resistances to its use because they have to grant to it a personal legitimacy, as the institutional legitimacy (the programs) or the social legitimacy (stemming from it as a modern tool that is used widely in industry) are not sufficient. Hence, the mediative, cognitive and personal components of the teachers (their history, perceptions of teaching, of algebra, etc.) come into play here. This also partly explains why not all instruments are treated alike in mathematics teaching and learning $\square$ Do teachers consider this distance "legitimate" with regard to their "epistemology" of mathematics on the one hand, and to the didactic potentialities they foresee on the other hand? The interviews carried out with novice teachers (Haspekian 2005a) show that this is not self-evident. Furthermore, if a certain distance is necessary for the tool be seen to be interesting, this distance involves a mathematical and didactic reorganisation and thus an additional workload for the teacher. As we saw above, not only are there new praxeologies to create (that the programs and the resources, however many, are not enough to release) but additional tasks arise for teachers as they consider the management of pupils' instrumental geneses in a new environment. 「ast, but not least, this management should lead pupils to mathematical concepts (variable, formula, etc.) that remain relevant to the traditional paper-pencil environment.

Finally, the integration (or not) of a new tool requires an equilibrium of these various elements. Do the teacher's own convictions about the expected benefits and/or the official directions to use the tool counterbalance the additional workload he/she can foresee in that task of integration? Moreover, a phenomenon of double genesis can come into play and add further complexities for teachers who are not very familiar with the tool, which is described later in the chapter. For the spreadsheet, one can assume that the praxeologies are far from the mathematical and didactic organisations currently practiced within early algebra in France. 
This idea of instrumental distance prompts a number of questions concerning spreadsheet integration within mathematics education such as: do the many resources available to teachers consider it? and How do teachers who have integrated spreadsheets take advantage of this distance in their practices?

The next section reports on a case study involving an experienced teacher during the first two years of her integration of spreadsheets into her teaching, showing that the evolution during the second year moves precisely in the direction of reducing this distance.

\section{Under standing practices with ICT: a case study on integr ating spreadsheets}

Taking into account the idea of distance, I turn to the question of the teaching practices, with some additional tools to support the associated analysis.

In a study concerning teachers' initial training involving the integration of CAS calculators, Trouche (1999, p. 307) had already noticed the importance of two factors relative to the teachers themselves: their degree of mastery of the tool and the range of their positivity or negativity of the representation/conception of its integra$\operatorname{tion}^{12}$. In the same way, the numerous works analysing practices inspired by the double approach (Robert \& Rogalski, 2002) underline that teachers' activity is not only related to the mathematical content to be taught or the learning experiences of the students but also to a number of teacher-related factors such as individuals exercising a $\mathrm{ob}$ which has its own constraints and freedoms. When considering ICT integration, it is relevant to take this personal component into account.

\section{Additional theoretical elements to analyse teachers practices}

The didactic and ergonomic approach (Robert \& Rogalski 2002) is an interesting theoretical support for the analysis of teachers' practices as it frames teacher's activity through different components, one of which is this important personal component. By turning the spotlight onto this personal component and because we want to take into account teachers' apprehension of the instrumental issues, I distinguish a professional instrument from a personal one (Haspekian 2006) and consider their corresponding instrumental geneses, professional and personal.

\section{Didactic and er gonomic appr oach (Robert and Rogalski, 2002)}

The didactic and ergonomic approach analyses practices by the mean of five components: cognitive, mediative, institutional, social, and personal. The cognitive and mediative components relate to the choices made by the teacher in the spatial, temporal and mathematical organisation of the lessons. These choices are made according to the teacher's personal component. The personal component relates to the teacher as a singular sub ect with his/her own history, practices, vision of mathematics, way of conceiving mathematics learning, teaching, etc. $\square$ et, the personal factor is not the only one to consider. Teachers are not completely free in their choices as they are more or less constrained by institutional and social dimensions. The institutional and social dimensions relate to the curricula, lesson duration, school social habits, mathematics teachers' habit, etc. 
In the case of ICT practices, instrumental aspects seem to interfere with each of these components. In particular, the personal component plays a crucial role in determining whether ICT in mathematics teaching is supported. For example, teachers integrate ruler and compass without any problem as they are accepted as part of the mathematical culture. This might be because historically, the ruler and compass played an essential and epistemological role in the development of mathematics. (Chevallard, 1992) This role and the number of mathematical problems generated by these traditional tools serve to legitimise their place in mathematics education. Is it the same for spreadsheets? How is their introduction in mathematics teaching ustified? Do teachers feel this tool relevant to their mathematics and the ways they learned, learn, do and teach mathematics?

The consideration of these questiond led to the use of the instrumental approach to analyse more locally some of the phenomena observed with ICT practices, in particular the teachers' professional instrumental genesis with the spreadsheet.

\section{Professional instrumental genesis}

This case study shows that, at the early stages, the way that teachers orchestrate and support pupils' instrumental geneses evolves year by year. Satring from the premise that the spreadsheet as an instrument for the teacher, which allows her to achieve some teaching goals, the process of instrumental genesis is considered from the teacher's perspective (Haspekian, 2006). The same artefact, the spreadsheet, becomes an instrument for pupils' mathematical activity and an (other) instrument for teacher's didactical activity. Thus, applying the instrumental approach to the spreadsheet is a teaching instrument created by the teacher through a professional genesis, two processes are highlighted:

- A process of instrumentalisation process as teachers instrumentalised the tool in order to serve didactic ob ectives. It is transformed from its initial functions and its didactical potentialities are progressively created or discovered im wasy that are appropriate for an educational tool.

- A process of instrumentation in which the teacher is required to incorporate within her (already stable) teaching schemes some new schemes that integrate the use of the tool. Progressively, the teacher will specify the use of the tool for a particular class of situations (i.e. take advantage of the spreadsheet for the learning of algebra learning) and will organise her activity in a way that becomes increasingly more stable for this class of situation (Ann's case already shows some regularities from year 1 to year 2).

The instrument that is created as a result of this process of professional genesis (spreadsheet as a tool to teach algebra) is different from the instrument built through a personal genesis (the spreadsheet as a tool of personal work of calculation, plotting, data treatment, etc.). From the same artefact, two instrumental geneses (that may interfere with each other according to the teachers) lead to two different instruments. The spreadsheet in these two situations is not at all the same instrument. The second one is close to the instrument we want pupils to build. The teacher's profesional genesis with the tool is much more complicated as it includes the pupils' instrumental geneses. Here again, the phenomena are imbricate and interfering. 
This notion of double instrumental genesis together with the didactic and ergonomic approach is used in the next section to analyse the observation of a teacher who is integrating the use of a spreadsheet in mathematics. The case of the spreadsheet provides a good exemplification of the phenomena that play in the development of ICT practices for at least two reasons. Firstly, the spreadsheet is a professional tool without any 'a priori' didactical functionality. In this case, the instrumental distance is not negligible and plays a considerable role in the difficulties surrounding the integration of spreadsheets. Secondly, the teacher has to turn this non-educational tool into a didactical instrument through a process of professional genesis, a process made more complex by this instrumental distance.

\section{A case study: Ann}

\section{in ICT integration}

The next section reports the data and subsequent analyses of a study that observed how a very experienced teacher integrated spreadsheets within her practices for the first time and the evolution of this integration during the subsequent year.

\section{The data}

Ann is not a trainee, she has taught mathematics for more than 10 years long, but she is not an expert with the use of technology within mathematics teaching and learning. She has already some experience of dynamic geometry software and now she is beginning to integrate spreadsheets in her classroom. In this first year, Ann's choices were motivated by her participation in a one-year research proect that focused on spreadsheet use for learning al gebra (Haspekian 2005a). The data that was collected included: observations of all of her spreadsheet lessons (6 sessions); teacher interviews before and after each session; and the students' spreadsheet files. At the end of the research, an interview collected Ann's thoughts and feelings about this experience.

Following the completion of the research, Ann continued to use spreadsheets in the following year. During this second year, I observed and recorded her first spreadsheet session and the subsequent session in a paper and pencil environment. I collected the problems as they were given to the students and the associated homework, and I carried out some interviews concerning her intentions for this second year. The resulting analyses showed an evolution of her practice. This evolution converges towards the characteristics of experts' practices described in the next section.

During the second year, Ann introduced spreadsheet not within algebra but within statistics (headcounts, frequencies and cumulative frequencies), after having seen these notions in paper pencil environment. In this context, some of the observed elements were surprising as the lesson revealed very little statistics and mostly centred on the tool use and functionalities, revealing unexpected mathematics such as notions of variable, formula and the distinction between numeric and algebraic functions. Of course, this reflects the influence of the first year of her experience, centred on algebra, but this does not explain the complete evolution (variations and regularities) summarised in Table 2 of Ann's choices for introducing spreadsheets:

\begin{tabular}{|c|c|c|}
\hline Use of spreadsheet & $\square$ ear 1 & $\square$ ear 2 \\
\hline
\end{tabular}




\begin{tabular}{|c|c|c|}
\hline Class level & $7^{\text {th }} \square$ rade (12 year old) & $8^{\text {th }} \square$ rade (13 year old) \\
\hline Old/new content & $\square$ ew & Statistics \\
\hline Mathematical Domain & $\square$ imited to computer classroom & Computer /ordinary classroom \\
\hline Spreadsheet location & $\square$ o & Individual and collective \\
\hline Synthesis & Mostly individual \\
\hline Interactions Teacher- & Piloted by teacher, limited role & Teacher and student. Im- \\
\hline Use of the video and col- \\
lective presentation
\end{tabular}

Table 2. Ann's approach to the introduction of spreadsheet in her teaching.

In both years, Ann met the institutional demand to integrate spreadsheets within her mathematics teaching but the way that she did this different in each year. Table 2 shows an evolution of two components. The mediative and cognitive components have evolved with respect to the chosen mathematical domain, the way that the spreadsheet was introduced, the level of the class that was chosen. This prompts the questions, Why did she evolve and How can we state more specifically her professional genesis with the tool?

Ann

with the spreadsheet as a didactical tool

Both years, Ann's activity with the spreadsheet is oriented by the goal of using it to teach algebraic concepts such as variables and formulae, for example, by using the copy funtion, or by profiting from the numerical feedback to infer the equivalence of two formulae.

This brings into play some usage schemes ${ }^{13}$ concerning the material and organisational aspects that are being developed from one session to another towards a more stable set of practices that concern: integrating the tool within a larger set of instruments (with the data proeector), using the data proector at the beginning of the lesson to make collective explanations, requiring the pupils to communicate and work in pairs, giving an instruction sheet and a pre-built file to save time, and regularly clicking on a cell to check whether pupils have edited a formula or numerical operation, or the numerical result.

In Ann's case, this professional genesis was not independent from her personal genesis with spreadsheet as the observations show how these interfered with each other. ${ }^{14}$. These interferences were made more complex by 
the fact that she wanted her pupils to manipulate the spreadsheet for themselves (one could imagine a spreadsheet usage only under a teacher's control) and learn mathematics as a result of this activity. As already stated, as the pupils' instrumental geneses forms part of the teacher's profesional genesis with the tool this leads to another interference.

Observation of some of Ann's activity in these first two lessons in her second year result from these interferences and an example of this now follows.

\section{The interfer ences betwen the teachers}

As already mentioned, Ann chose to introduce the spreadsheet to a different class within the domain of statistics. Fig. 3 is an abstract of the task she developed for her pupils that shows the corresponding spreadsheet file with the pre-edited formula built by Ann:

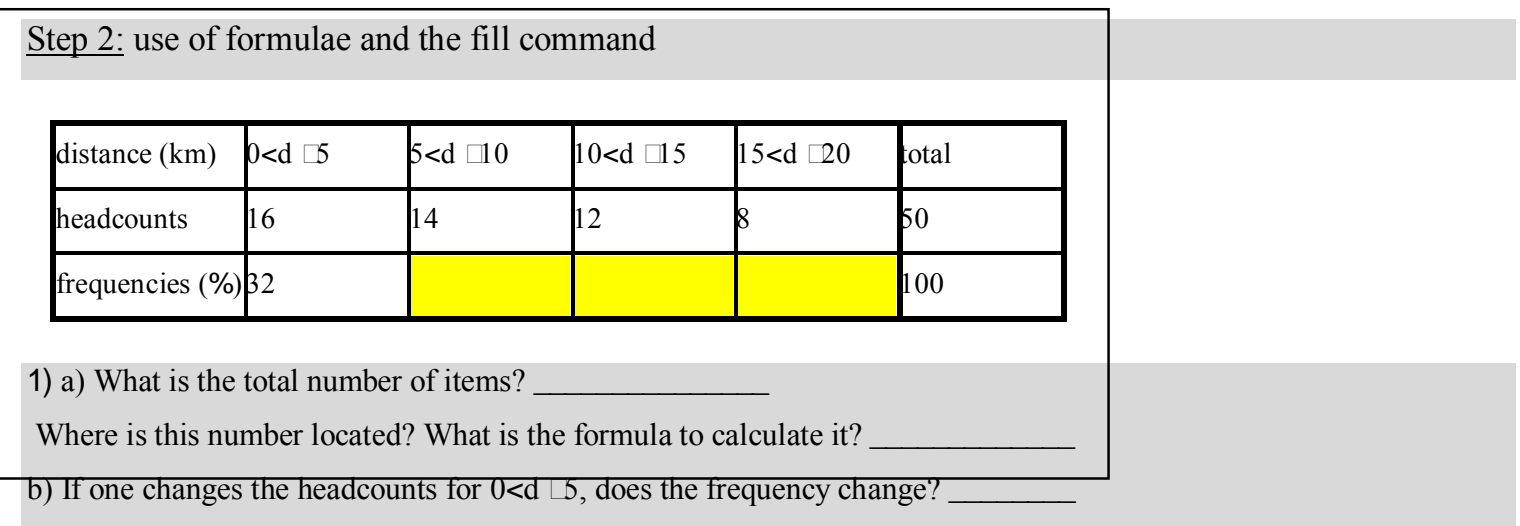

\begin{tabular}{|c|c|c|c|c|c|c|}
\hline & A & $\mathrm{B}$ & $\mathrm{C}$ & $\mathrm{D}$ & $E$ & $\bar{F}$ \\
\hline \multicolumn{7}{|l|}{1} \\
\hline \multicolumn{7}{|l|}{2} \\
\hline 3 & Etape 2: & & \multicolumn{3}{|c|}{ calcul de fréquences } & \\
\hline 4 & & & & & & \\
\hline 5 & distance $(\mathrm{km})$ & $0<d \leq 5$ & $5<d \leq 10$ & $10<d \leq 15$ & $15<d \leq 20$ & total \\
\hline 6 & effectif & 16 & 14 & 12 & 8 & =SOMME(B6:E6) \\
\hline 7 & fréquence (\%) & $=B 6 / \$ F \$ 6^{*} 100$ & & & & 100 \\
\hline
\end{tabular}

Fig.3 Ann's final version of the formulae

It is interesting to notice that Ann modified this file three times. In its first version, the formula calculating the frequency (in B7) was $=B 6^{\star} 100 / 50$. This formula, if copied along row 7 calculates the correct frequencies for the corresponding data of row 6 . But it is not adequate regarding the question $b)^{15}$.

The day before the lesson, Ann realised the mistake and changed the formula to $=\mathrm{B} 6 / \mathrm{F} 6^{*} 100$. She confided she did not yet feel very comfortable with spreadsheets. Her own instrumental genesis with spreadsheets as a mathematical instrument probably plays a role here as we also see that the key point of the problem comes from the spreadsheet as a didactic-oriented instrument. From the point of view of the spreadsheet as a calculationoriented instrument, the formula was adequate. The didactical aim (showing the mathematical dependency between numbers and frequencies) led Ann to ask the question b), which resulted in an incorrect formula. She did not realise this when she first constructed her formula. At that moment, the personal instrument stands at the front of the scene, and obscures the professional instrument and its associated didactical aims (the question b.). 
Interference between the personal and the professional instrument can be seen again within the continuation of the story. The new formula, $\square \mathrm{B} 6 / \mathrm{F} 6 \square$ 100, is now adequate for question $b$, but still not convenient if we consider the next question (Fig.4) for inverse reasons $\square$ Ann wants pupils to copy the formula in order to fill row 7 and meet this filling functionality with the automatic incrementation of cell references (B6 becomes C6...). This time, this is part of her goals for students' instrumental geneses.

3) Complete the table using the formula in B7:

Recopy the formula on the right. (see instructions below for the "cell recopy")

What is the formula contained in C7? D7? E7?

Fig.4 The next stages of the task

The formula above, if copied along row 7, is no longer valid, as the cell referring to the total, F6, will change into $\square 6, \mathrm{H} 6$... along the row. A solution to this problem is to fix the cell F6 in the recopy by using the " $\square$ " sign. But Ann did not want this functionality to appear in the first spreadsheet session as it was above the level of instrumentation she wanted for her pupils at that moment. When she built her new formula for question $b$, the was not in her mind and she did not include it, forgetting that it would create false results at question 3 . The day before the session, we had a phone call to finalise our meeting during which she realised the new issue and included the $\square$ as a last-minute decision $\square$

Thus, this time the formula was 'wrong' with regards to an instrumental goal, that is the use of the $\square$ symbol was above Ann's instrumental ob ectives and she did not have it in her mind. It is neither easy nor trivial to adapt to meet all of the constraints, particularly as she had already changed her very first version of formula for a mathematical aim, now she had to change it again for an instrumental aim. This time, the professional-oriented instrument overrode the personal one, by taking into account pupils' geneses and the level of instrumentation that she wanted them to reach.

These successive formulae disrupted the session and finally Ann put the $\square$ sign into the formula but expected to avoid speaking about it with the pupils. Unfortunately, it arose of course during the session $\square$ Being compelled by pupils' questions to explain, she only said that it is not important to write it with a paper and pencil environment. Then, when a pupil came to the board to write the spreadsheet formula, he forgot the $\square$, the "division by ero Error" appeared after filling and Ann said "now you happy? but did not explain the message nor the division by ero. $^{16}$ In that sense, the perturbation due to the “ $\square$ ” sign appears as one of Clark-Wilsons’ lesson hiccups (Clark-Wilson 2010) defined as:

These were the perturbations experienced by the teachers during the lesson, triggered by the use of the technology that seemed to illuminate discontinuities in their knowledge and offer opportunities for the teachersôepistemological development within the domain of the study (Clark-Wilson Chapter XX in this book, p. )

Inter pretation of the complex and divided geneses on the part of the teacher 
The example above shows how the double genesis of the teacher side may interfere with pupils' geneses. The spreadsheet's constraints interacted with the teacher's goals and didactical expectations (she wanted to introduce a basic level of spreadsheet functionalities did not want to go any further). This is evidence that she has not yet turned her personal instrument into a mathematics-teaching instrument. This process is made more complex by the different geneses at stake. As we saw in the example, it is constrained by:

- The teachers aims for the mathematical learning, i.e. concerning statistics and algebra.

- The pupils' instrumentation that is, how to support pupils' mathematical work through their interactions with the spreadsheet i.e. the mathematical headcount-frequency dependence through the change of the frequency cell after changing the value of the headcount cell.

- The pupils' instrumentalisation, that is the choice of functionalities be used, the desired schemes of use i.e. relative references and the automated incrementation of cell references using the copy function, but not yet the absolute references, the $\square$ sign and its specificity in the filling of formulae.

The simultaneous management of these constraints is not easy as the spreadsheet is not 'a priori' a didactical instrument. Ann's case study shows that such an instrument is only developed progressively through a complex professionally-oriented genesis.

\section{How to understand Ann}

The way that Ann evolved from the first year to the second is related to this professional instrumental genesis.

In the previous section, using both the notions of distance and double instrumental genesis, I have described the beginning of such a genesis and analysed locally the associated complexity through the case of Ann's use of spreadsheet. In particular, the way that teachers orchestrate and support pupils' instrumental geneses evolves year after year.

Ann's goal is to use the spreadsheet to teach algebraic concepts and she develops some instrumented schemes of action for this that concern the material aspects, the organisation of the sessions and the orchestration of pupils' instrumental geneses. Ann's practice with speadsheets includes, for instance, the following elements were evident that emerged during the first year and seemed to stabilise in the second year:

- using a data pro ector at the beginning of the session to make collective explanations;

- requiring pupils to communicate and work in pairs;

- giving pupils a sheet of instructions and a pre-built computer file to save time;

- regularly "click" on individual cells to check whether pupils have edited a formula or numerical operation, or even directly the numerical result.

Some other elements of her orchestrations were modified during the second year:

- The use of the spreadsheet with a higher level of class, i.e. with $\square$ rade 8 instead of $\square$ rade 7 .

- Fewer 'new' concepts were introduced at one time, i.e. the introduction of the spreadsheet and the introduction of new mathematical notions. 
- She changed the mathematical domain change i.e. it was introduced within with statistics, which seemed to Ann to be more appropriate than algebra.

- A deeper articulation between social and individual schemes, something that Trouche (2005) has stressed the importance of within the process of instrumental geneses. In the interview, Ann said she had not organised enough moments of "mutualisation" (whole class discussions) and she explicitly wished to take care of this point in the second year.

The next section observes these evolutions more closely, and shows that they all appear to converge in the direction of reducing the instrumental distance.

\section{Changing the class level: Higher level of class}

This modification comes with the change of the mathematical domain. In the French curriculum the spreadsheet is explicitly mentioned for the teaching and learning of statistics for $\square$ rade 8 pupils. In the $\square$ rade 7 curriculum the spreadsheet appears in a more general and vague way and teachers are required to reflect more deeply to define its potential for the learning of mathematical notions. These notions appear more distant from spreadsheet mathematics than within the $\square$ rade 8 curriculum, where the spreadsheet is more clearly specified wit respect to precise mathematical notions. Thus, by choosing this level Ann was able to reduce the distance and match the official prescriptions more easily. In addition, during year 1, Ann did not find the $\square$ rade 7 pupils’ instrumentalisation process easy. They had difficulty to fill cells, to select a single cell and to edit a formula. Older pupils seemed to be more skilful and problems that were linked to instrumentalisation should interfere less with the mathematical work. With $\square$ rade 7, the manipulations of the tool seemed more difficult and the tool appeared less transparent.

\section{The old/new knowledge game with respect to the mathematical and instrumental content}

During year 1, Ann introduced a new instrument at the same time as she introduced some new mathematical content (algebraic notions). The relationship between the old knowledge and the new knowledge is different in year 2, which tends to reduce the instrumental distance by lessening the amount of newness. For example, all of the mathematical notions at stake in the spreadsheet session (headcounts, frequency, cumulative frequency) had already be seen previously by the pupils in the paper and pencil environment. This experience (new environment with "already-seen" concepts) will then serve Ann as a base to introduce algebraic notions (new concepts in an "already-seen" instrument).

\section{Domain changing}

There are at least three reasons why the mathematical domain chosen by Ann in year 2 also reduces the distance with respect to algebra. The domain of statistics is usually seen to conform more closely to the representations 
within a spreadsheet than the domain of algebra. Furthermore, institutional pressure is less important in statistics than algebra, which is a more classic and traditional domain that is strongly linked to paper pencil mathematics. On the contrary, nowadays statistics is to fit more closely to the use of technology. Finally, within the language of the spreadsheet, one can find terms that are more commonly used within statistics whereas the distance to the traditional vocabulary of algebra is wider (and important) (Haspekian 2005 b).

\section{Moments of mutualisation and articulation with paper and pencil mathematics}

In her second year, Ann introduced some moments of mutualisation during her spreadsheet sessions. In the interview, she affirmed her will to increase the similarity between these sessions and the traditional ones. She felt that it was necessary to increase the links to the paper and pencil mathematics. For example, she started the sequence with a paper and pencil session, then revisited the same notions in a spreadsheet session, and then returned to the work done with spreadsheet within a subsequent paper and pencil session.

Thus, at a range of different levels, Ann's modifications tended to minimise the spreadsheet's instrumental distance. All of these actions contributed to reduce the distance with paper-pencil and to mix in a greater proximity the mathematics within these two environments.

Another remarkable point is to notice that Ann'evolution gains some characteristics of experts' practices, as evidenced in the research. This is explored in the next section.

\section{Bringing together the results from differ ent research}

In this section, I am bringing together Ann's case study with the results of a second research study. This latter research studied the practices of what we have called "expert" teachers that is, non-novice teachers who have been integrating ICT and spreadsheet for a long time and who are also "ICT trainers" and "spreadsheet trainers" within the context of mathematics teacher training. By comparing the practices of these expert teachers alongside the practices of preservice teachers, I have highlightened some overarching characteristics of practices with ICT.

An interesting outcome of this cross analysis is that Ann's evolution with the spreadsheet converges towards the characteristics of experts' practices. The next section presents this in more detail by first giving some results and regularities found in the data collected with "expert" and novice teachers.

\section{Some characteristics of experts practices with ICT}

I begi by posing the question, Are there regularities of practice amongst teachers who have successfully integrated the spreadsheet? In making a comparison with novice teachers, what are the characteristics of the expert teachers' practices that seem to contribute fundamentally to their success? How do they manage the pupils' instrumental geneses? And how do they take into account the instrumental distance generated by the spreadsheet? In order to answer these questions, I looked for regularities at the following levels: in teachers' conceptions; in 
the evolution of their practices; and in the changes that reslted from this evolution. The notions of coherence and stability as defined by Robert \& Rogalski can enlighten these questions:

the coherence of the system of the practices of a teacher $(\square)$ would prevent the introduction of inconsistent elements with this system (Robert \& Rogalski, 2002, p. 521).

Within an alternative theoretical framework, the considerations of $\square$ agrange are in the same direction. $\square$ agrange (2000) underlines that the introduction of a tool into mathematics lessons generates an upheaval of the praxeologies, which may hinder its integration into the practices. How did expert teachers deal with these obstacles?

As said in the introduction, I carried out questionnaires and interviews with trainees and expert teachers. The questionnaire for trainees contained 41 questions divided in 3 parts (see Appendix A). The first was general information about the teacher (age, training etc.), the second concerned their general opinions about the use of technology and the third concerned their use of spreadsheet in mathematics classroom and their opinions about this. There were 23 questionnaries returned by the trainees and four additional group discussions (in groups of 3 or 4) were held in which we allowed the trainees to discuss their answers to parts 2 and 3 of the questionnaire in order to gain abetter understaindg of their opnions. The questionnaire given to the expert teachers was an identical one and six individual interviews lasting 2-3 hours were conducted about their effective practices with ICT and spreadsheets. We also collected all of their teaching materials, which evidenced their progression in use of the spreadsheet, examples of tasks, frequency of use. etc.

The research study compares the trainees with the experts (Haspekian 2005a) and outlines some common findings about the novices, such as their obvious difficulties in perceiving the potentialities of the tool and to conceive mathematical and classroom organi $\lceil$ ations, which as yet they had not seen or experienced. It also suggested some convergence of practice amongst the experts that can be connected to their successful integration of spreadsheets.

The first result concerns the nature of the tasks chosen for a spreadsheet use. Parts 2 and 3 of the questionaire included a set of different spreadsheet tasks that included very basic use of the spreadsheet as a calculator to a more interesting use that took greater advantage of the spreadsheet's potential. These latter tasks were based on research situations mentioned in Capponi 2000, Ar arello \& al. 2001, and Roano \& Sutherland 1997, and they had been analysed by their authors as being positive for mathematics learning. In the questionnaire we were presented different ways of using spreadsheets and asked the teachers to choose which of these situations they found interesting for mathematics teaching and learning. The results of this study concured with those from other research (־aborde, 2001, Monaghan, 2004), that is novice teachers who are non-expert in the use of the spreadsheet have difficulty in the potential of the tool and in identifying interesting situations for its use. The choices of the beginner teachers, and their accompanying reasons, were systematically opposed to those of the expert teachers, which corresponded to the interesting situations. Thus, the teachers' first approach to the use of spreadsheets did not take advantage of the tool's potential. As Artigue recalls, the observed (and quite understandable) tendency amongst novice users is to use use technological tools not for their epistemic value (as a 
support to understand mathematical ob ects) but only for their pragmatic value (to produce results quickly and easily) within tasks that are very similar to those given in traditional paper and pencil tasks (Artigue, 2002).

In the analysis of the expert teachers' practices and the subseqient comparison of these findings with the novice pratices, a set of common characteristics appears. This prompts the question as to whether there fundamental elements contributing to teachers' success in the integration of spreadsheets. The first element is the importance of taking into account not a single tool but a system of instruments. This confirms the importance of the instrumental distance as these characteristics are a way to minimise the distance imposed by the spreadsheet. Another common characteristic was the fact that, using this system of instruments, these teachers play an old/new game concerning the mathematical content with equal attention to the various technological tools that they integrate. This means that they alternate new/old instrument with new/old content and do not try to introduce for example a new instrument with new concepts. This game also helps to articulate the work within technology with the work with paper and pencil.

These two characteristics provide an economic way to both manage the class in ICT sessions, and to manage the pupils' instrumental geneses. For example, concerning the mathematical content, one teacher said that having "a way of making revisions by bringing something more". As for another, he had "the same notions presented in two different environments". Another expert teacher interviewed said that she systematically works the same notion using by hand methods after an ICT session, and combines paper-calculator-spreadsheet and so on: "I make links non-stop, again and again $\square$ "

For all of these expert teachers, the integration of the spreadsheet is based upon this orchestration of a whole system of instruments. As they perceive the spreadsheet as more complex, they introduce it to their pupils after other software. This allows:

- time saving on the management of the class in ICT sessions (introduce the classroom, organise the didactic contract, etc.).

- time saving with respect to the instrumental geneses with the spreadsheet as some aspects have been addressed through other technological tools (physical manipulation of the materials, the computer room, virtual manipulation of files, etc.).

Within the common characteristics, we also found an increased attention paid to the questions of "mutualisation" and "socialisation", which was accomplished in two ways. Firstly, the expert teachers all organised their sessions with the pupils working in pairs and secondly, the teachers have developed the habit to use the data proector in order to mututalise the scattered knowledge of the pupils leading to more homogenous mathematical and instrumental knowledge.

Table 3 reiterates the common characteristics that appear to contribute fundamentally to the expert teachers' sucessful integration of the spreadsheet:

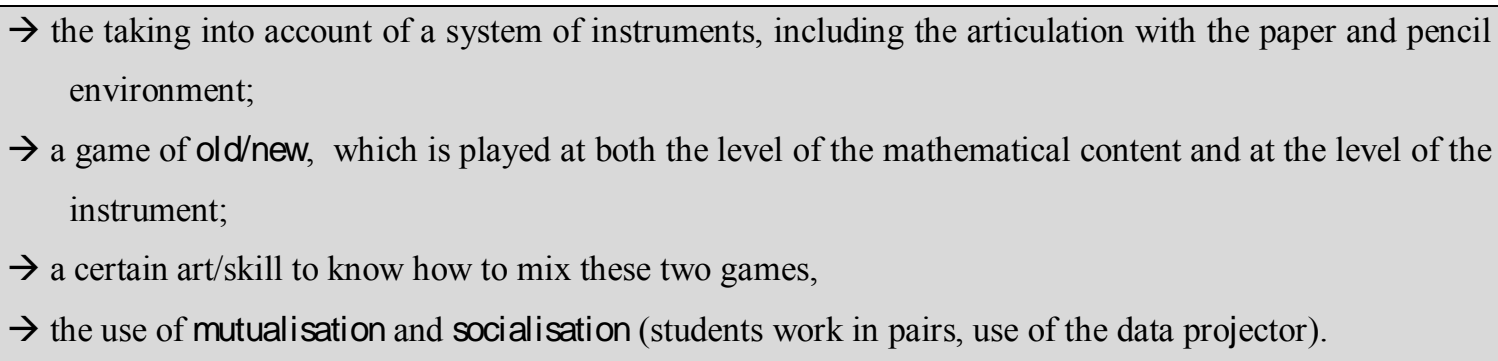


Table 3. Some common elements found in experts' practices

What is noticeable is that some connections can be seen then between these characteristics and Ann's evolution of practice as a result of the changes she introduced in the second year.

\section{Reducing instrumental distance: Towards experts}

In the analysis of the expert teachers, there were some common characteristics in their sucessful integration of ICT, in particular concerning spreadsheets. In this section, I will show that Ann's evolution, as analysed previously, tends towards some of these characteristics and gives an indication of the importance of these characteristics.

First, as seen in both cases, we find the tendency to minimise the instrumental distance. Actually, some of Ann's evolutions can be explained in terms of a reduction of the distance, either by making this distance more explicit or by increasing the times when she alternated the work in both the spreadsheet and paper and pencil environments, which enriched both of them. This "mixing" of different environments and, in particular, the articulation within the paper and pencil environment, appeared precisely as a common characteristic of the teachers who have integrated the spreadsheet successfully. Thus, it is interesting to notice that Ann's professional genesis follows the same path (even though she did not achieve a level of expert practice with respect to all characteristics). For instance, the moments of mutualisation and articulation with paper and pencil mathematics by Ann are more successful in the second year, whereas she did not pay much attention to this in the first year.

The old/new game mentioned above is another characteristic found in the expert teachers' practices. They manage ICT integration by ad usting and adaptating the degree of novelty to incorporate a degree of complexity of the tool. When introducing a complex artefact such as the spreadsheet, they choose familar content, which has already been ontroduced within the paper and pencil environment. Once the students have more familiarity with the spreadsheet with more familiar mathematical content, they use it subsequently to develop new mathematical knowledge.

Again, it can be noted Ann's evolution is moving in that direction. In the first year, she introduced both the spreadsheet and a new mathematical domain (algebra), whereas in the second year, she changed her aaproach to introduce spreadsheets by choosing an old mathematical domain, statistics. The pupils, having already seen statistics in a paper and pencil environment, then meet the new instrument, a spreadsheet, in the context of old content. Ann's long term intention, as stated in her interview, is to use the spreadsheet within the context of algebra, but now she intened to do this after the have seen spreadsheets in another area of mathematics (an old one) in order not to intruduce both new artefact and new contents.

Of course, when I observed Ann at the beginning of the second year, she had not achieved all of the common characteristics of the expert teachers as listed in Table 3, but this is not surprising. She is at a stage within her professional genesis with the spreadsheet where she was integrating it for the second time in her career. It is predictable that her practices are not completely stabilised and that these will continue to evolve. For instance, 
for the expert teachers, the game 'old/new' concerns not only the mathematical content and not only one tool, but a complex system of instruments that incorporate paper and pencil articulations. Expert teachers do not expect pupils to first meet computers through the use of spreadsheets but with other software, such as dynamic geometry software, which presents a small instrumental distance than the spreadsheet. In that way, pupils meet the computer classroom, the basic instructions about the use of the computers, the files, the opening and closing sessions, the articulation within the paper and pencil envrioenment, the work in pairs, and so on, with a software that seems easier to integrate than the spreadsheet. Once they are used to these basic manipulations and orchestrations on a more familiar old instrument, they are ready to meet a new, more difficult one, such as the spsreadsheet.

\section{Discussion and perspectives}

In the section, I will come back to the general purpose of this work, which was to gain a better understand of teachers' practices with technology and the process of their instrumental geneses. To this aim, the previous sections have introduced some important elements and lead me to draw conclusions on their instrumental professional geneses with ICT, which I will discuss here:

I have analysed Ann's evolutions in terms of a reduction of the instrumental distance, either by making this distance more explicit, or by increasing the opportunities to alternate work in the two environments, enriching both of them. This distance is more or less important, depending upon the tool. The integration of spreadsheets in the teaching and learning mathematics constitutes a significant creative task for teachers as the tool is not given with any didactical functionality. It requires a professional instrumental genesis on teacher's side that differs from the teacher's personal genesis with the tool (even if they interfere) and different again from that of the pupils. Here again, one can hypothesise that a professional instrumental genesis with dynamic geometry software is easier.

These combined considerations helped the analysis of Ann genesis and the conclusion that Ann tended to acquire in her evolution some of the characteristics found as commonalities among the expert teachers as follows:

- Articulation with paper-pencil mathematics

- Moments of mutualisation and socialisation

- The game old/new, concerning the mathematical content (not yet on the instruments for Ann).

These are all included in the experts' characteristics Table 3. The inverse is not true because Ann did not reach all the characteristics of the experts. For example, in her evolution, this exploitation of different instruments to facilitate the introduction of spreadsheets does not appear yet, but it seems reasonable to think that one does not gain all of the characteristics of the expert teachers after only one year. This instrumental professional genesis is a long process, as is any instrumental genesis. This raises questions for the professional training of teachers such as: How to take into account the importance of working within a "system" of instruments instead of the isolated tools? How to take into account the "socialisation" dimension? Is it possible through these improvements to shorten the time needed for the instrumental professional genesis?

I conclude on the fact that these results are at the stage of hypotheses, as key issues in ICT integration. To extend this result, a larger scale study is needed with more than 6 expert teachers, and with some observations of 
their actual practices in the classrooms. The fact that Ann's evolution tends towards some of their common characteristics is a simple indication that these elements may constitue good "candidates" of ICT practices, but this hypothesis does requires further research.

Other questions remain for research. For example, concerning ICT integration and evolutions of teachers' practices, a criterion, which we have seen as important in this chapter, is the notion of intrumental distance. If it does reveal itself as a source of difficulty for teachers, then it is crucial to advance in the comprehension of ICT impact on mathematics and the way teachers take into account instrumental distance, drawing some important characteristics from experts practices. However, it is also necessary to determine which elements may counterbalance this distance and may support the process of tool integration, such as institutional in unctions, or the tool's epistemic value and its didactical design. As technology evolves, the instrumental distance can thus be important for educational tool designers. As for the epistemological legitimacy, it also relates to teachers' representations and beliefs about ICT and mathematics. This dimension has been investigated in other research, see for instance Norton, McRobbie and Cooper (2000), who conclude that teachersôresistance is related to their beliefs about mathematics teaching and learning. If knowledge and beliefs about teaching mathematics with ICT are actual barriers, can this dimension be considered in teachersôtraining and how?

Finally, the issue of "isolated" potentialities of technology for mathematics education does not solve the problem of their integration in teaching practices (for example in teaching algebra in the case of the spreadsheet), due to this instrumental distance. Several questions remain and a better understanding of the characteristics of experts' practices and of course the way to develop these, may be important also in a training perspective. This remains an open field for further research.

Acknowledgments I would like to thank Rebecca Freund, and the anonymous second reviewer, who very carefully reviewed the English of the text.

\section{Refer ences}

Arganbright, D. (1984). The Electronic Spreadsheet and Mathematical Algorithms. The College Mathematical bournal 15: 148157 Artigue, M. (2002). ־earning mathematics in a cas environment: The genesis of a reflection about instrumentation and the dialectics between technical and conceptual work. International Journal of Computers for Mathematical Learning, 7, 245-274.

$\operatorname{Ar} \_$arello, F., Ba $\square$ ini, $\square$., Chiappini; $\square$. (2001) A model for analysing algebraic processes of thinking $\square$ In R. Sutherland, T. Assude, A. Bell and R. $\square$ ins (dir.), Perspectives on school al gebra, vol.22, p. 61-81. Kluwer: Academic Publishers.

Baker, $\square$ and Sugden, S. (2003) Spreadsheets in Education $\square$ The First $25 \square$ ears, Spreadsheets in Education (elSiE): $\square$ ol. 1-1, Article 2.

Balacheff, $\square$. (1994). $\square$ a transposition informatique. $\square$ ote sur un nouveau probl $\square$ me pour la didactique. In M. Artigue (Ed.), Vingt ans de Didactique des Mathématiques en France, pp. 364-370. $\square$ renoble : $\square$ a pens $\square$ e sauvage.

Balanskat, B., Blamire, R., Kefala, S. (2006). The ICT Impact Report.A review of studies of ICT impact on schools in Europe. Report written by European Schoolnet in the framework of the European Commission http://ec.europa.eu/education/pdf/doc254「en.pdf 
Bruillard \& al (2008) Rapport de recherche du proet Didatab, disponible en ligne http://www.stef.enscachan.fr/didatab/fr/comp $\backslash \mathrm{yc}$ fr.htm

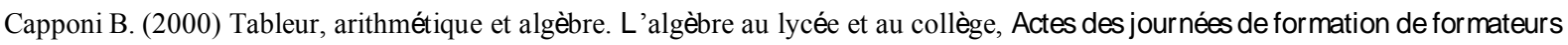
1999, p.58-66, IREM de Montpellier.

Chevallard, $\square$. (2007). Readusting Didactics to a Changing Epistemology. European Educational Research Journal, 6(2), 131-134.

Chevallard, $\square$. (1992). Int $\square$ gration et viabilit $\square$ des ob $\Subset$ ets informatiques dans l'enseignement des math $\square$ matiques. In B. Cornu (Ed.), $\mathrm{L}$ (pp. 183-203). Paris: Presses Universitaires de France.

Clark-Wilson, A. (2010a). Connecting mathematics in a connected classroom: Teachers emergent practices within a collaborative learning environment. British Congress on Mathematics Education, BSR $\square$ M Proceedings 30 (1). University of Manchester.

Clark-Wilson, A. (2010b). How does a multi-representational mathematical ICT tool mediate teachers pedagogical knowledge concerning variance and invariance? $\mathrm{PhD}$ thesis, Institute of Education, University of $\square$ ondon.

Coulange, $\square$. (1998) $\square$ es probl $\square$ mes "concrets $\square$ mettre en $\square$ quation" dans 1enseignement. Petit x n 47. 33-58

Drivers, P., Kieran, C., Mariotti, M.A. (2010). Integrating technology into mathematics education: theoretical perspectives. In C. Hoyles, \& ־-B. 『agrange (Eds.), Mathematics education and technology - Rethinking the terrain (pp. 89-132). $\square$ ew $\square$ ork/Berlin: Springer.

$\square$ uin, D., Ruthven, K. Trouche, $\square$. (2004). The didactical challenge of symbolic calculators: turning a computational device into a mathematical instrument. $\square$ ew $\square$ ork: Springer.

Haspekian, M. (2011) The co-construction of a mathematical and a didactical instrument. In M.Pytlak, E.Swoboda \& T.Rowland (Eds.), Proceedings of the seventh Congress of the European Society for Research in Mathematics Education. CERME 7, R esvow.

Haspekian, M. (2006). Evolution des usages du tableur. In Rapport interm diaire de 1ACI-EF Genèses d'usages professionnels des technologies chez les enseignants, http://gupten.free.fr/ftp/GUPTEn-RapportIntermediaire.pdf

Haspekian, M. (2005a). Intégration d

as des tableurs. $\mathrm{PhD}$ thesis, University Paris 7. tel.archives-ouvertes.fr/tel-00011388/en/

Haspekian, M. (2005b). An "Instrumental Approach" to study the integration of a computer tool into mathematics teaching: The case of spreadsheets, International Journal of Computers for Mathematical Learning, 10 (2), 109 141.

Hsiao, F. S. T. (1985). Micros in mathematics education - Uses of spreadsheets in CA $\sqsubset$. International bournal of Mathematical Education in Science and Technology, 16(6): 705-713

aborde, C. (2001). Integration of technology in the design of geometry tasks with Cabri geometry. International Journal of Computers for Mathematical Learning, 6/3, 283-317.

$\square$ aborde, C. et Capponi, B. (1994) Cabri-g $\lceil$ om tre constituant d un milieu pour lapprentissage de la notion de figure $\mathrm{g}\lceil$ om trique, Recherche en didactique des mathématiques vol. 14/1-2

$\square$ agrange, B. (2000). ¿integration dinstruments informatiques dans 1enseignement : une approche par les techniques, Educational Studies in Mathematics, 43, 1-30

Monaghan $\square$ (2004) Teacher $\$$ activities in technology-based mathematics lessons. International Journal of Computers for Mathematics Learning. 9, 327-357.

$\square$ orton, S., McRobbier, C. $\square$, Cooper, T. $\square$ (2000) Exploring secondary mathematics teachers' reasons for not using computers in their teaching: Five case studies. Journal of Research on Computing in Education, 33 (1)

Par $\square y s \square$, B. (1988) $\square$ oir et savoir $\square$ la repr $\llbracket$ sentation du "per $\sqsubset$ u" et du "su" dans les dessins de la g $\square$ om $\square$ trie de lespace. Bulle tin del'APMEP, 364

Robert, A. \& Rogalski, $\square$ (2002). $\sqsubset$ e syst $\llbracket$ me complexe et coh $\llbracket$ rent des pratiques des enseignants de math $\square$ matiques : une double approche, Revue canadienne de I

2, 505-528.

Rabardel, P. (2002). People and technology -a cognitive approach to contemporary instruments; http://ergoserv.psy.univ-paris8.fr

Ro ano T., Sutherland R. (1997) Pupils strategies and the Cartesian method for solving problems: the role of spreadsheets, Proceedings of the $21^{\text {st }}$ International PME Conference, vol.4, p.72-79. 
Ruthven, K. (2007). Teachers, technologies and the structures of schooling. In D.Pitta-Panta 1 , \& $\square . P h i l i p p o u(E d s$.$) , Proceed-$

ings of the fith congress of the European Society for Research in Mathematics Education, (pp.52-68), $\square$ arnaca.

Stacey K., Chick H., Kendal M. (2004), The Future of the Teaching and Learning of Algebra, The 12th ICMI Study, Kluwer Academic Publisher.

Trouche, $\square$. (2005). Instrumental genesis, individual and social aspects. In D. $\square$ uin, K. Ruthven \& $\square$. Trouche (Eds.), The didactical challenge of symbolic calculators: turning a computational device into a mathematical instrument (pp.197-230). $\square$ ew $\square$ ork, $\square \square$ : Springer.

Trouche, $\square$. (2003). Managing the Complexity of Human/Machine Interaction in a Computer Based $\square$ earning Environment: $\square$ uiding Student's Process Command Through Instrumental Orchestrations. CAME3: Learning in a CAS Environment: Mind-Machine Interaction. Reims.

\section{Notes}

\footnotetext{
${ }^{1}$ The name taken in the initial French research is "Dan"; in this chapter, it is translated to "Ann" to make it more sound a girl's name.

${ }^{2}$ This term is explained in section 3 .

3 There is no research at world scale comparing integration of geometry software and spreadsheets, but all local studies that can be found indicate a better penetration of geometry software than spreadsheets (see the examples cited in Haspekian 2005a)

${ }^{4}$ The reader can find a brief explanation of the basic functionalities, in a didactic approach, in Haspekian 2005a, pp.18-23

${ }^{5}$ One can see in Coulange (1998) at which point the algebraic methods rest on rules of didactic contract and remain fragile for pupils ages 15-16 who, facing atypical problems, provide correct answers in rupture with the algebraic rules of the didactic contract

${ }^{6}$ analyse/synthesis, trial/refinement and equations

${ }^{7}$ because the algebraic character of the formulas is restricted to their utility in carrying out and automating calculations, the focus is not on providing an operational language to analyse and handle relations (Capponi \& Balacheff 1989).

${ }^{8}$ Because of this dialectic "it is not possible to clearly distinguish between these two processes" (Trouche, 2003).

${ }^{9}$ We limit ourselves to the case of the material artefacts, but the ergonomic approach is extended to 'psychological' artefacts: symbols, signs, cards, etc.

${ }^{10}$ This raises difficulties for teachers, see the experiment described in Haspekian 2005b

${ }^{11}$ Mathematical ob ects are not isolated, in educational institutions they live through mathematical and didactical organisations that are praxeologies: a quadruplet composed of tasks, techniques, technologies (discourse about the techniques: explanations, ustifications $\square$ ) and theories. See (Chevallard, 2007).

${ }^{12}$ The words "representation" and "conception" are not problematised in this chapter and used in their common senses.

${ }^{13}$ Rabardel (2002) distinguishes the usage schemes (related to the material dimension of the tool) from the schemes of instrumented action (related to the global achievement of the task, with goals and intentions).

${ }^{14}$ It may not be the case for all teachers: unlike Ann's case, the first instrument can be already constituted in a more advanced way, long before trying to make it a didactical instrument.

${ }^{15}$ The formula refers to the value 50 for the total. If one changes the value of any headcount, then the total will change and the formula becomes wrong

${ }^{16}$ Increment of references after filling makes the formula refer to empty cells. By default, empty cell are treated in formulas as if they contain the value 0 , this option that can be changed.
} 